\title{
Endothelin and active renin levels in essential hypertension and hypertension with renal artery stenosis before and after percutaneous transluminal renal angioplasty
}

\author{
Kim Edwards Teunissen, Cornelis T. Postma, Brigit C. van Jaarsveld*, \\ Frans H.M. Derkx* and Theo Thien
}

\begin{abstract}
Objective To determine whether active renin and endothelin levels in venous plasma differ between patients with renal artery stenosis and patients with primary hypertension. Among the patients with renal artery stenosis we also compared active renin and endothelin levels between subjects who had been cured or whose blood pressure had improved after treatment of the stenosis and those without a beneficial reaction after such treatment.
\end{abstract}

Methods We measured immunoreactive endothelin and active renin levels in peripheral venous plasma before and $1 \mathrm{~h}$ after angiotensin converting enzyme inhibition in 25 patients with primary hypertension and in 27 patients with hypertension and renal artery stenosis.

Percutaneous transluminal angioplasty was performed in 21 patients of the latter group. For 11 patients of this group, hypertension was cured or there was an improvement, whereas 10 other patients did not respond to this treatment. Baseline active renin and endothelin levels were compared between these groups, as were the clinical characteristics of the patients.

Results Baseline endothelin levels were similar in members of the renal artery stenosis [median $3.6 \mathrm{pg} / \mathrm{ml}$ (range 1.4-11.7)] and in members of the no stenosis group [5.0 pg/ml (1.5-8.0)]. Also baseline endothelin levels did not differ between members of the successfully treated $[3.6 \mathrm{pg} / \mathrm{ml}(1.8-8.9)]$ and unsuccessfully treated groups [3.75 pg/ml (1.4-8.3)]. Angiotensin converting enzyme (ACE) inhibition failed to cause a significant change in endothelin level in

\section{Introduction}

The endothelins are vasoactive peptides of which up to now three different isopeptides have been identified. Endothelin-1 (ET-1) is a potent vasoconstrictor produced by endothelial cells [1]. In the kidney it is produced both in endothelial and in non-endothelial cells [2]. No storage granules of ET-1 have been discovered thus far and approximately $25 \%$ of ET-1 synthesized is secreted into the general circulation [3]. Endothelins have been thought to have a considerable impact on the vascular tone both in normal physiological and in diseased states. However, plasma endothelin levels have not been found to members of any of the patient groups. Although baseline renin levels differed significantly between members of the renal artery stenosis and no stenosis groups [40.2 $\mu \mathrm{u} / \mathrm{ml}(0.9-543)$ versus $13.4 \mu \mathrm{u} / \mathrm{ml}$ (2.5-931), $(P<0.05)$ ], there was no difference in baseline renin levels between the members of successful and unsuccessful groups [25.7 $\mu \mathrm{u} / \mathrm{ml}(\mathbf{9} .2-475.6)$ versus $65.3 \mu \mathrm{u} / \mathrm{ml}$ (12.3-542.6)]. ACE inhibition caused a significant increase in renin level in members of all groups except the unsuccessfully treated group.

Conclusions Circulating endothelin levels did not differ significantly among patients with essential hypertension, hypertension with renal artery stenosis and proven renovascular hypertension and, although the renin-angiotensin system was clearly activated in members of the renovascular hypertension group, ACE inhibition did not affect their endothelin levels. These results suggest that endothelin does not play a direct role in the pathophysiology of renovascular hypertension.

Journal of Hypertension 1997, 15:1791-1796

Keywords: renal artery stenosis, human, hypertension, percutaneous transluminal angioplasty, endothelin, active renin, renovascular hypertension

From the Departments of Medicine of the University Hospital Nijmegen and *University Hospital Dijkzigt Rotterdam, The Netherlands.

Requests for reprints to Dr C.T. Postma, Department of Internal Medicine, University Hospital, Postbox 9100, 6500 HB Nijmegen, The Netherlands.

c) Rapid Science Publishers ISSN 0263-6352

be elevated in essential hypertension [4,5]. Endothelin levels are elevated in pulmonary hypertension and renal failure [5,6]. Because vasoactive substances take such an important part in the pathophysiology of renovascular hypertension $(\mathrm{RVH})$, it is worth considering whether endothelins are involved in at least some of the vascular reactivity mechanisms operating in this form of high blood pressure.

Specific information about the role of endothelin in RVH is, however, incomplete. Several findings suggest that endothelin could be involved in RVH through involve- 
ment with the renin-angiotensin system. First, endothelial cell culture studies have shown that hypoxia [7] and angiotensin II (Ang II) induce synthesis and release of endothelin [8]. Angiotensin converting enzyme (ACE) inhibition attenuates this release [9]. Second, Ang II stimulates endothelial production of endothelin and thereby potentiates contractions in response to noradrenaline in mesenteric resistance arteries of spontaneously hypertensive rats [10]. Furthermore, Sventek et al. [11] found vascular overexpression of ET-1 gene in one-kidney, one clip hypertensive rats but only during the late phase of two-kidney, one clip hypertensive rats. Also several clinical studies have been reported but they produced contradictory results in which endothelin levels were found to be either normal or elevated in patients with renal artery stenosis (RAS) [12-15].

The aim of the present study was to investigate a possible role of endothelin in the pathophysiology of RVH in humans. We studied endothelin and renin levels in peripheral venous blood before and after ACE inhibition in members of the following groups of hypertensive patients: subjects with essential hypertension, persons with hypertension and RAS, patients whose hypertension was cured or alleviated by percutaneous transluminal renal angioplasty (PTRA) treatment of RAS and patients whose hypertension was not lessened by PTRA treatment of RAS.

In studying these specific patient groups, we supposed that we would be able to employ ACE inhibition and responses to PTRA as tools to select out RAS patients with true RVH, allowing us to compare endothelin levels of these renovascular hypertensives with those of other hypertensives. Given the evidence on endothelin summarized above, we hypothesized that ACE inhibition would cause not only an increase in renin levels but also, via a decrease in Ang II levels, a decrease in circulating endothelin levels in patients with RVH. Furthermore, the renin: endothelin level ratio before and after ACE inhibition could provide a reliable marker for distinguishing true RVH from essential hypertension cases with and without RAS.

\section{Patients and methods}

For 52 hypertensive patients newly referred to the outpatient clinic, the physicians in charge deemed it necessary to perform intra-arterial digital subtraction angiography. Indications for angiography were treatment-resistant hypertension, defined as blood pressure values above $160 / 90 \mathrm{mmHg}$ despite two-drug treatment, and other clinical clues suggestive of RAS, such as an abdominal bruit and a sudden rise of a known blood pressure.

Clinical and biochemical data of these patients were collected. Blood pressure was measured by using a standard mercury sphygmomanometer with the patient supine. The mean of three consecutive readings was used. The possibility that these patients had other forms of secondary hypertension was assessed by determination of serum electrolyte levels, plasma renin activity, aldosterone levels and catecholamine levels. Urinary excretions of creatinine, metanephrines and protein were also measured. Endogenous creatinine clearance was calculated from serum creatinine level measurements [16]. The urine screenings, together with microscopy of urine sediments were used to exclude the possibility that these patients had parenchymatous renal disease. Patients with other forms of secondary hypertension and patients with renal insufficiency were excluded from this study. For determination of plasma concentrations of active renin and endothelin, venous blood was collected into tubes containing EDTA. Samples were centrifuged immediately at $0^{\circ} \mathrm{C}$ and stored at $-20^{\circ} \mathrm{C}$ until assay. Active renin and endothelin-1 levels were measured by radioimmunoassays, as described previously $[17,18]$. The antiserum for endothelin-1 exhibited $67 \%$ cross-reactivity with endothelin-2 and $84 \%$ with endothelin-3. PTRA was performed as a standard procedure via the femoral approach under direct high-resolution fluoroscopy. The reactions of blood pressure to the procedure were determined according to the internationally accepted criteria. A patient with blood pressure below $90 \mathrm{mmHg}$ without medication was considered cured. Improvement was defined as a decline in blood pressure by at least $15 \%$ with the same medication or a decline by $10 \%$ with discontinuation of administration of at least one antihypertensive drug. Patients who had been cured and patients who had improved were placed in the successfully treated group and all patients with other outcomes in the unsuccessfully treated group. A stenosis was considered significant if the vascular lumen was found by angiography to have narrowed by more than $50 \%$. P'TRA was performed in patients with RAS for whom there was no contra-indication to the treatment and who consented to be subjected to the procedure. Patients were administered $300 \mathrm{mg}$ acetylsalicylic acid a day starting 1 day before the procedure and continuing for 3 months afterwards.

\section{Statistical analysis}

Values are expressed as medians (ranges) unless indicated otherwise. Comparisons of the data within groups were analysed by Wilcoxon's paired signed rank test for parameters with non Gaussian distributions. Student's paired $\mathrm{t}$ test was used for parameters with normal distributions. Differences between groups were assessed by unpaired tests. When appropriate the Bonferroni correction for multiple comparisons was applied. The correlations of endothelin levels in members of the RAS, the primary hypertension, the successfully treated and the unsuccessfully treated groups either with renin level or with 
endogenous creatinine clearance were analysed by Spearman's rank correlation test. Statistical significance was assumed at a 5\% level, two-sided.

\section{Results}

Of the 52 patients with hypertension who had undergone diagnostic digital subtraction angiography, 25 had no RAS and were diagnosed as having essential hypertension. The remaining 27 patients proved to have RAS. There were 20 unilateral and seven bilateral cases. The clinical characteristics of the patients with and without RAS are summarized in Table 1 . The groups differed only in baseline systolic blood pressure, that of the RAS group being significantly higher than that of the group without stenosis [186 mmHg (140-246) versus $168 \mathrm{mmHg} \quad(120-215)$, $P<0.05]$. Furthermore, atherosclerosis was the major aetiological factor for RAS in our study rather than fibromuscular dysplasia (FMD, 20 versus seven patients).

Twenty-one of the 27 patients with RAS were treated by PTRA of the stenosis. Of the 21 patients treated, 11 exhibited decreases in blood pressure in response to this treatment. The remaining 10 patients did not respond to this treatment. The clinical characteristics of these patients are summarized in Table 1. Bilateral RAS was found in patients in the unsuccessfully treated group more often than it was in patients in the successfully treated group (four versus one patient). Blood pressures of all patients with FMD-related RAS responded to PTRA treatment. Conversely, the unsuccessfully treated group was comprised entirely of patients with RAS as a result of atherosclerosis. The five patients with FMD RAS were also the five women in the successfully treated group. Thus, although male patients with atherosclerotic RAS were distributed evenly between the successfully and unsuccessfully treated groups, the female patients with atherosclerotic RAS did not respond to treatment by PTRA.
The baseline renin level in members of the RAS group was significantly higher than that in members of the essential hypertension group [40.2 $\mu \mathrm{u} / \mathrm{ml}(0.9-543)$ and $13.4 \mu \mathrm{u} / \mathrm{ml}$ (2.5-931), respectively, $P=0.049]$. The baseline level of endothelin did not differ significantly between RAS [3.6 pg/ml (1.4-11.7)] and essential hypertension $[5.0 \mathrm{pg} / \mathrm{ml}(1.5-8.0)]$ cases.

The baseline renin level in members of the successfully treated group [25.7 $\mu \mathrm{u} / \mathrm{ml}(9.2-475.6)]$ was not significantly different from that in members of the unsuccessfully treated group $[65.3 \mu \mathrm{u} / \mathrm{ml}(12.3-542.6)]$ and neither were the baseline endothelin levels [3.6 pg/ml (1.8-8.9) and $3.75 \mathrm{pg} / \mathrm{ml}$ (1.4-8.3), respectively].

ACE inhibition caused significant rises in active renin levels in members both of the RAS and of the essential hypertension group, [from $40.2 \mu \mathrm{u} / \mathrm{ml}$ (1-543) to $98.6 \mu \mathrm{u} / \mathrm{ml}(3.2-2004) ; P=0.001$ and from $13.4 \mu \mathrm{u} / \mathrm{ml}$ (2.5-931) to $20.4 \mu \mathrm{u} / \mathrm{ml}$ (2.9-1432), $P=0.03$, respectively]. In addition, the RAS patients who responded to treatment by PTRA displayed a significant rise in renin levels after ACE inhibition [from $25.7 \mu \mathrm{u} / \mathrm{ml}$ (9.2-475) to $72.8 \mu \mathrm{u} / \mathrm{ml}$ (10.4-2004), $P=0.001$, whereas members of the unsuccessfully treated group failed to respond to ACE inhibition in terms of a significant rise in renin levels from baseline [from $65.3 \mu \mathrm{u} / \mathrm{ml}(12.3-542.6)$ to $145 \mu \mathrm{u} / \mathrm{ml}$ (11.3-1298)].

The differences (i.e. after-before values) in renin levels before and after ACE inhibition did not differ significantly between members of the RAS group [47.6 $\mu \mathrm{uml}(-28.5$ to 1528) and members of the group with essential hypertension $[3.1 \mu \mathrm{u} / \mathrm{ml}(-106$ to 500$)]$. This also held true for the successfully treated group [47 $\mu \mathrm{uml}(-2$ to 1528$)$ and the unsuccessfully treated group [50 $\mu \mathrm{u} / \mathrm{ml}(-28$ to 847$)]$. The relative differences between baseline values and those after ACE inhibition were not significant for any of the groups.

Table 1 Clinical characteristics of hypertensive patients with or without renal artery stenosis, successfully or unsuccessfully treated by percutaneous transluminal renal angioplasty

\begin{tabular}{lcccc}
\hline & $\begin{array}{c}\text { No stenosis } \\
(\mathrm{n}=25)\end{array}$ & $\begin{array}{c}\text { Renal artery } \\
\text { stenosis } \\
(\mathrm{n}=27)\end{array}$ & $\begin{array}{c}\text { Treatment } \\
\text { successful } \\
(\mathrm{n}=11)\end{array}$ & $\begin{array}{c}\text { Treatment } \\
\text { unsuccessful } \\
(\mathrm{n}=10)\end{array}$ \\
\hline Men/women & $13 / 12$ & $15 / 12$ & $6 / 5$ & $6 / 4$ \\
Age (years) & $48(24-63)$ & $52(29-76)$ & $48(29-71)$ & $55(44-76)$ \\
Unilateral/bilateral stenosis & $20 / 7$ & $10 / 1$ & $6 / 4$ \\
Aetiology: atherosclerosis/FMD & $168(120-215)$ & $186(140-246)^{\ddagger}$ & $180(140-210)$ & $197(158-246)$ \\
Baseline SBP (mmHg) & $101(70-120)$ & $108(90-145)$ & $108(90-130)$ & $109(96-145)$ \\
Baseline DBP (mmHg) & $26.3(17.8-43.0)$ & $25.1(17.6-39.6)$ & $26.2(19.1-30.5)$ & $25.2(21.6-29.6)$ \\
BMl (kg/m²) & $98.3(26.4-256.2)$ & $82.3(23.2-153.3)$ & $89.3(45-153)$ & $75.0(32-134)$ \\
ECC (ml/min) & $12 / 13$ & $14 / 13$ & $7 / 4$ & $5 / 5$ \\
Smokers/non-smokers & $1 / 1$ & $1 / 0$ & $0 / 0$ & $0 / 0$ \\
With/without diabetes mellitus & & & &
\end{tabular}

Values are expressed as medians (ranges). FMD, fibromuscular dysplasia; SBP, systolic blood pressure; DBP, diastolic blood pressure; BMI, body mass index; ECC, endogenous creatinine clearance. ${ }^{*}$ No relation to the seven bilateral RAS patients. ${ }^{\dagger} \mathrm{All}$ FMD patients were women. ${ }^{\ddagger} P<0.05$, versus no stenosis. 
Fig. 1

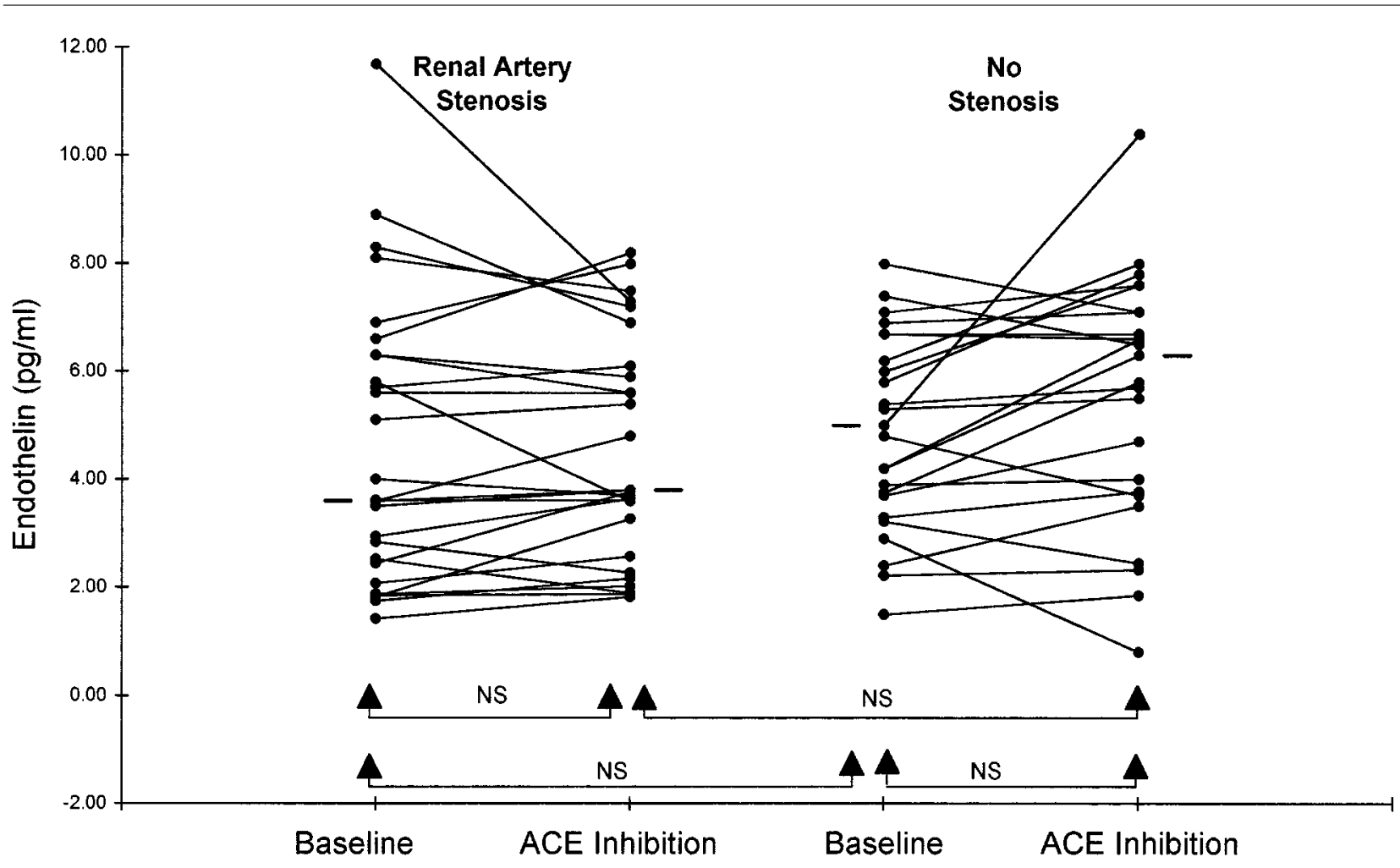

Comparison of circulating endothelin levels in patients with hypertension before and after angiotensin converting enzyme (ACE) inhibition. Horizontal bars, medians.

The patients with essential hypertension had a baseline endothelin level of $5.0 \mathrm{pg} / \mathrm{ml}(1.5-8.0)$ and the subjects with RAS had a baseline endothelin level of $3.6 \mathrm{pg} / \mathrm{ml}$ (1.4-1.7), which values were not significantly different (Fig. 1). In members of the successful treatment group baseline endothelin level was $3.6 \mathrm{pg} / \mathrm{ml}(1.8-8.9)$ and in members of the unsuccessful group it was $3.75 \mathrm{pg} / \mathrm{ml}$ (1.4-8.3); also these values were not significantly different (Fig. 2).

ACE inhibition caused no significant change in endothelin levels in members of any of the four study groups. Furthermore, the differences and relative differences in endothelin levels before and after ACE inhibition did not differ significantly between members of the RAS group and the essential hypertension group and between members of the successfully and the unsuccessfully treated groups.

The renin : endothelin level ratio at baseline was significantly higher for the RAS group in comparison with that for the essential hypertension group $[9.4 \mu \mathrm{u} / \mathrm{pg}$ (0.1-131.5) versus $2.5 \mu \mathrm{u} / \mathrm{pg} \quad(0.4-221.7)$, respectively, $P=0.020]$. ACE inhibition further increased the significant difference between renin : endothelin level ratios for the RAS and essential hypertension groups [26.5 $\mu \mathrm{u} / \mathrm{pg}$
(0.4-554.2) versus $3.6 \mu \mathrm{u} / \mathrm{pg} \quad(0.5-227.3)$, respectively $P=0.005]$

The renin : endothelin level ratio at baseline was the same for the group that responded as it was for the group that did not respond to treatment by PTRA. Furthermore, ACE inhibition failed to cause a significant difference between values of this ratio for these patient groups. The difference in ratios before and after ACE inhibition did not differ significantly between the successfully and unsuccessfully treated groups.

Endothelin levels in peripheral venous blood were not correlated either to renin levels or to endogenous creatinine clearances for all four groups.

\section{Discussion}

The results of the present study indicate that endothelin levels in peripheral venous blood under baseline resting conditions are comparable among patients with essential hypertension, hypertension combined with RAS and RVH. In addition, ACE inhibition and thus a decrease in Ang II levels did not affect endothelin levels in patients with essential hypertension, patients with essential hypertension combined with RAS and patients with RVH. Although the renin : endothelin level ratio differed signif- 


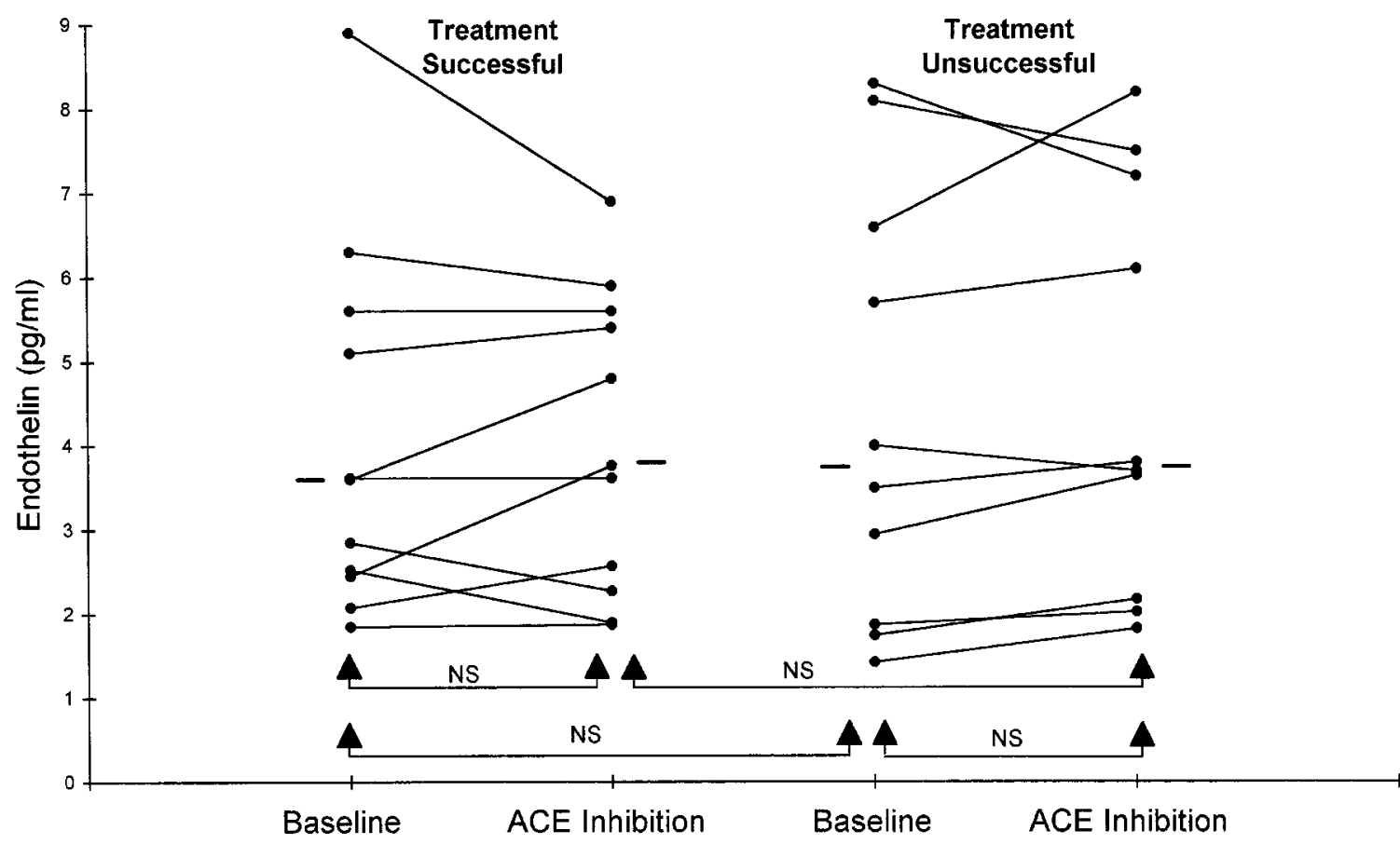

Comparison of circulating endothelin levels in patients for whom percutaneous transluminal renal angioplasty had been successful and unsuccessful at lowering blood pressure before and after angiotensin converting enzyme (ACE). Horizontal bars, medians.

icantly between the groups with and without RAS, this was largely, if not completely, due to the significant difference in renin levels. This argument also applies to the renin : endothelin level ratio after ACE inhibition, which displayed an even more significant difference.

In dividing the group of patients with RAS into those who responded to PTRA and those who did not, we attempted to distinguish between RAS leading to RVH and RAS occurring concomitantly with essential hypertension. Interestingly, among the patients with RAS, administration of the ACE inhibitor caused renin levels to rise only in members of the group who responded to treatment by PTRA. Therefore, the fact that endothelin levels did not differ between these groups and were not affected differently by ACE inhibition makes the hypothesis that endothelin plays a role in the pathophysiology of RVH less plausible.

It is possible that the production and release of endothelin were not affected during the relatively short $60 \mathrm{~min}$ sampling period used in this study. However, an oral dose of captopril reaches its maximum plasma level $1 \mathrm{~h}$ after ingestion and the maximum blood-pressure-lowering affect occurs $60-90 \mathrm{~min}$ after ingestion. Thus it can be concluded that, 60 min after ingestion, while captopril is affecting the renin-angiotensin system and other mechan- isms involved in regulation of blood pressure, regulation of endothelin production seems not to be altered.

Plasma levels of endothelin both in essential hypertension and in RVH patients both with and without ACE inhibition have been investigated by several other groups. Results of most studies [12-15] concur with the results of the present study. Two groups who studied endothelin levels in blood samples taken directly from renal arteries and veins found endothelin levels in healthy controls, patients with essential hypertension and patients with RAS to be within the normal range [14,15]. Januszewicz et al. [19] reported that the degree of activation of the renin-angiotensin system had no effect on the endothelin levels, which were also not elevated in their patients with RAS. In contrast, Giussani et al. [12] did find an increase in plasma endothelin levels in patients with RAS and elevated Ang II levels.

Several in-vitro studies with isolated arteries from rats and humans have shown that the vasoconstricting effect of infusion of endothelin-1 on vascular smooth muscle cells is blunted in subjects with mild forms of hypertension [19-21]. Furthermore, vascular smooth muscle cells from spontaneous hypertensive rats display lower than normal responses of intracellular calcium levels to infusion of endothelin-1 but exhibit higher than normal responses to 
infusion of Ang II [22,23]. These results suggest that endothelin does not affect vasoreactivity once hypertension has been established and thus possibly this could explain why endothelin levels are not elevated in most hypertensive (patients with essential hypertension and patients with RVH) subjects studied. Possibly endothelin plays a role in vasoreactive events leading to chronic hypertension. However, Sventek et al. [11] recently showed that, although the one-kidney one clip Goldblatt hypertensive rat exhibits vascular overexpression of the endothelin-1 gene, the two-kidney, one clip Goldblatt hypertensive rat only does so during a late phase. This late expression could also be linked to renal failure or to an inability of the lungs or kidneys to clear the endothelin. Thus, although many studies, including the present one, could not show that circulating endothelin plays a role in maintaining RVH, endothelin's role in the early phase of RVH has yet to be sufficiently studied.

With the exception of baseline systolic blood pressure, there were no significant differences among the clinical characteristics of the groups studied. Male and female patients were distributed equally among groups. In a recent study [24] it was found that plasma endothelin levels are modulated by the menstrual cycle. Although this new knowledge does not directly affect the results of the present study, all future studies of this type should take the effect of the menstrual cycle on endothelin levels into consideration when experimenting on female subjects. Of the 27 patients with RAS, seven were diagnosed as having bilateral stenosis. Furthermore, four of the unsuccessfully and one of the successfully treated patients had bilateral RAS. In such cases, both renal arteries were treated by PTRA. It was, however, beyond the scope of this study to evaluate the difference between unilateral and bilateral stenosis with regard to hypertension, renin levels and endothelin levels.

In conclusion, the present study showed that circulating levels of endothelin in patients with essential hypertension, patients with hypertension with RAS and patients with true RVH are similar. Although the reninangiotensin system in patients with RVH was activated, as shown by a significant increase in plasma renin activity after ACE inhibition, endothelin levels were not correlated to the renin levels and were not affected by ACE inhibition. These results do not support the hypothesis that production of endothelin in RVH patients is dependent on Ang II.

\section{References}

1 Levin ER: Endothelins. N Engl J Med 1995, 333:356-363

2 Nord EP: Renal actions of endothelin. Kidney Int 1993, 44:451-463.

3 Nakamura S, Naruse M, Naruse K, Demura H, Uemura H: Immunocytochemical localization of endothelin in cultured bovine endothelial cells. Histochemistry 1990, 94:475-477.

4 Schiffrin E, Thibault G: Plasma endothelin in human essential hypertension. Am J Hypertens 1991, 4:303-308.
5 Shichiri M, Hirata Y, Ando K, Emori T, Ohta K, Kimoto S, et al.: Plasma endothelin levels in hypertension and chronic renal failure. Hypertension 1990, 15:493-495.

6 Tomita K, Ujiie K, Nakanishi T, Tomura S, Matsuda O. Ando K. et al: Plasma endothelin levels in patients with acute renal failure [letter] N Engl J Med 1989, 321:1127.

7 Kourembanas S, Marsden PA, McQuillan LP, Faller DV: Hypoxia induces endothelin gene expression and secretion in cultured human endothelium. J Clin Invest 1991, 88:1054-1057.

8 Kohno M, Horio T, Yokokawa K, Kurihara N, Takeda T: C-type natriuretic peptide inhibits thrombin- and angiotensin II-stimulated endothelin release via cyclic guanosine $\mathbf{3}^{\prime}, \mathbf{5}^{\prime}$-monophosphate. Hypertension 1992 19:320-325

9 Yoshida $\mathrm{H}$, Nakamura M: Inhibition by angiotensin converting enzyme inhibitors of endothelin secretion from cultured human endothelial cells. Life Sci 1992, 50:PL195-200.

10 Dohi Y, Hahn AWA, Boulanger CM, Buhler FR, Luscher TF: Endothelin stimulated by angiotensin II augments contractility of spontaneously hypertensive rat resistance arteries. Hypertension 1992, 19:131-137.

11 Sventek P, Turgeon A, Garcia R, Schiffrin E: Vascular and cardiac overexpression of endothelin-1 gene in one-kidney, one clip Goldblatt hypertensive rats but only in the late phase of two-kidney one clip Goldblatt hypertension. J Hypertens 1996, 14:57-64.

12 Giussani M, Cianci M, Gazzano G, Airoldi F, Turolo L, Ghio F, et al.: High levels of angiotensin II can increase endothelin-1 production in patients with renovascular hypertension (RVH) [abstract]. J Hypertens 1994, 12 (suppl 3):S192.

13 Schwartz Sorensen S, Egeblad M, Eiskjær H, Madsen B, Brockner Nielsen $\mathrm{C}$, Sihm I, et al.: Endothelin in renovascular and essential hypertension. Blood Pressure 1994, 3:364-369.

14 Schreij G, van Es P, Schiffers PMH, de Leeuw PW: Renal arterial and venous endothelin in hypertensive patients with or without renal artery stenosis. Blood Pressure 1994, 3:370-374.

15 Poch E, Jimenez W, Feu F, Coca A, Botey A, Bosch J, et al.: Increased plasma endothelin concentration in atherosclerotic renovascular hypertension. Nephron 1995, 71:291-296.

16 Cockroft DW, Gault MH: Prediction of creatinine clearance from serum creatinine. Nephron 1976, 16:31-41.

17 Derkx FHM, De Bruin RJA, Van Gool JMG, Van den Hoek MJ, Beerendonk $\mathrm{CCM}$, Rosmalen $\mathrm{F}$, et al:: Clinical validation of renin monoclonal antibody-based sandwich assays of renin and prorenin, and use of renin inhibitor to enhance prorenin immunoreactivity. Clin Chem 1996, 42:1051-1063.

18 Kraayenbrink AA, Dekker GA, Van Kamp GJ, Van Geijn HP: Endothelial vasoactive mediators in preeclampsia. Am J Obstet Gynecol 1993 169:160-165.

19 Januszewicz A, Symonides B, Lapinski M, Lewandowski J, Januszewicz M, Rowinski $\mathrm{O}$, et al.: Endothelin-1 and neuropeptide $\mathrm{Y}$ plasma concentrations in renal venous blood of hypertensive patients with unilateral renal artery stenosis. J Hum Hypertens 1995, 9:815-820.

20 Dohi Y, Luscher TF: Endothelin in hypertensive resistance arteries: intraluminal and extraluminal dysfunction. Hypertension 1991, 18:543-549.

21 Deng LY, Schiffrin E: Effects of endothelin-1 and vasopressin on resistance arteries of spontaneously hypertensive rats. Am J Hypertens 1992, 5:817-822.

22 Nguyen PV, Yang X, Li G, Deng LY, Fluckiger J, Schiffrin E: Contractile responses and signal transduction of endothelin-1 in aorta and mesenteric vasculature of adult spontaneously hypertensive rats. Can J Physiol Pharmacol 1993, 71:473-483.

23 Touyz RM, Tolloczko B, Schiffrin E: Mesenteric vascular smooth muscle cells from SHR display increased $\mathrm{Ca}^{2+}$ responses to angiotensin II but not to endothelin-1. J Hypertens 1994, 12:663-673.

24 Polderman KH, Stehouwer CDA, Van Kamp GJ, Dekker GA, Verheug FWA, Gooren LJG: Influence of sex hormones on plasma endothelin levels. Ann Intern Med 1993, 118:429-432. 